\title{
Study on Toughness Improvement of a Rosin-Sourced Epoxy Matrix Composite for Green Aerospace Application ${ }^{+}$
}

\author{
Dongyuan Hu ${ }^{1}$, Xvfeng Zhang ${ }^{2}$, Xiaoling Liu ${ }^{1, *(\mathbb{O})}$, Zhen Qin ${ }^{3}, \mathrm{Li} \mathrm{Hu}^{3}$, Chris Rudd ${ }^{4}$ \\ and Xiaosu Yi ${ }^{1,2, *}$ \\ 1 Advanced Materials and Composites Department, University of Nottingham Ningbo China, 199 Taikang \\ East Road, Ningbo 315000, China; dongyuan.hu2@nottingham.edu.cn \\ AVIC Composite Co. Ltd., High-tech Park, Shunyi District, Beijing 101300, China; 010xufeng@sina.com \\ Shanghai Key Laboratory of Spacecraft Mechanism, 3888 Yuanjiang Road, Minhang District, \\ Shanghai 201109, China; qinzhen981621@163.com (Z.Q.); rocketeer_hu@outlook.com (L.H.) \\ 4 College of Science and Engineering, James Cook University, 149 Sims Drive, Singapore 387380, Singapore; \\ chris.rudd@jcu.edu.au \\ * Correspondence: xiaoling.liu@nottingham.edu.cn (X.L.); xiaosu.yi@nottingham.edu.cn (X.Y.) \\ + Dedicated to Prof. Dr.-Ing. Ortwin Hahn for his 80th birthday. Xiaosu Yi and his research team.
}

Received: 19 October 2020; Accepted: 5 November 2020; Published: 10 November 2020

\begin{abstract}
A high temperature epoxy resin was formulated by using a rosin-sourced anhydride-type curing agent, i.e., maleopimaric acid (RAM), and a two-component epoxy consisting of an E51-type epoxy and a solid phenolic epoxy to form a bio-sourced green matrix resin. The glass transition temperature of the final resin was $238^{\circ} \mathrm{C}$ Carbon fiber composite prepreg and was manufactured and laminated into composite specimens. Interleaving Toughening Technology (ITT) was applied to the laminates by using Polyamide interleaf veils. The interlaminar fracture toughness and compression after impact (CAI) strength were investigated and showed that the opening Mode I interlaminar fracture toughness GIC and the Mode II interlaminar fracture toughness GIIC of the specimens with interleaves were significantly improved from $227.51 \mathrm{~J} / \mathrm{m}^{2}$ to $509.22 \mathrm{~J} / \mathrm{m}^{2}$ and $1064.3 \mathrm{~J} / \mathrm{m}^{2}$ to $1510.8 \mathrm{~J} / \mathrm{m}^{2}$, respectively. Correspondingly, the drop-weight impact test shows that the interleaves reduced the impact damage area from $20.9 \%$ to $11.3 \%$ of the total area, and the CAI residual strength was increased from $144 \mathrm{MPa}$ to $191 \mathrm{MPa}$. Meanwhile, mechanical tests showed that the in-plane properties of the interleaved laminates were slightly reduced due to carbon fiber volume fraction reduction. In conclusion, the high glass transition temperature, fracture toughness and CAI behaviour make the green resin matrix composite a potential candidate for aerospace applications.
\end{abstract}

Keywords: rosin-sourced epoxy resin; interleaving toughening; glass transition temperature; toughness; CAI; in-plane mechanical properties

\section{Introduction}

Carbon fiber reinforced polymer matrix composites (CFRCs), mostly the thermosetting epoxy matrix composites, have been widely used in the aerospace industry because of their performance advantages such as light weight, high specific stiffness and strength, and fatigue and corrosion resistance. However, it is well known that all of the epoxies used today in aerospace are petroleum-sourced, i.e., they are all originated from non-sustainable fossil resource. Facing the world-wide challenge in environment, resources and sustainability, the aerospace industry has to adapt to the global need to decrease its environmental impact and greenhouse gas emissions, especially for commercial air transport [1]. Additionally, living on a planet with limited resources, another important sustainability 
goal is hence to reduce the consumption of non-renewable materials. Today's aviation industry is thus looking for bio-sourced materials for green aviation and green manufacturing as green alternatives [2].

Starting in 2016, European and Chinese scientists and engineers were working together in the ECO-COMPASS project to develop aeronautical composites with a reduced environmental footprint [3]. One of the objectives of ECO-COMPASS was to provide a preliminary assessment of a bio-sourced epoxy matrix composite and its usability in aviation [4]. This was an intermediate temperature epoxy cured with a rosin-anhydride-type curing agent with around 30\% bio-content [5]. It was noticed that the glass transition temperature, i.e., $T_{\mathrm{g}}$, of the rosin-sourced epoxy matrix composites reinforced with glass fiber was about $191-193^{\circ} \mathrm{C}$, which was much higher than conventional epoxy composites (typically c. $110{ }^{\circ} \mathrm{C}$ ). The higher $T_{\mathrm{g}}$ is possibly attributed to the bulky fused ring structure of the rosin-anhydride curing agent, imposing a considerable restriction on the segmental mobility between the cross-links [6]. Obviously, the higher glass transition temperature is beneficial for structural composites used in aviation.

However, as is well-known, compared with amine cured epoxies, anhydride cured epoxies generally show higher rigidity, lower curing shrinkage and more sustainability, but more brittleness [7-9]. The aerostructures from CFRCs are typical required to be resistant against impact delamination and damage, which is generally related with interlaminar fracture toughness and compression after impact strength, thus epoxy matrix composite laminates generally need to be toughened. Traditionally, epoxy matrix CFRC laminates are toughened by introducing thermoplastic components into the thermosetting matrix resin to form a bi-continuous granular structure in a manner of reaction-induced phase separation and phase coarsening [10-16]. However, such a complex phase structuring is highly dependent on the thermodynamic and kinetic conditions of the two polymer components, i.e., the thermoplastic toughness modifier and thermosetting epoxy matrix, making the toughening usually restrictive $[17,18]$.

Thermosetting polymer matrix CFRC laminates can also be toughened by interleaving non-woven textile veils to construct an interpenetrating thermoplastic network in the interlaminar region [19-26]. One of the major benefits of the so-called interleaving toughening technology (ITT) is its independence of the thermodynamic and kinetics of the polymer phases. It is also demonstrated that CFRC laminates of high electrical conductivity and high toughness can be simultaneously achieved by electrically functionalizing the interleaving material [27-29].

In the present paper, a similar rosin-anhydride sourced curing agent and a high-temperature epoxy matrix resin cured with the agent was developed and reported. Carbon fiber reinforced composite laminates (CFRCs) using the high-temperature epoxy matrix were then toughened by interleaving a specially designed polyamide veil. The in-plane mechanical properties and out-of-plane properties were tested in terms of Mode I and II interlaminar fracture toughness and Compression After Impact (CAI) strength, as well as tensile, flexural, compression and interlaminar shear strength etc. The toughening mechanism was studied by microstructure observation. It was finally found that the rosin-sourced epoxy matrix CFRC could provide higher $T_{\mathrm{g}}$, higher toughness, higher CAI and promising mechanical properties for use in aviation.

\section{Experimental}

\subsection{Materials}

Similar to the intermediate temperature epoxy resin, a high temperature epoxy matrix resin was formulated using a rosin-sourced anhydride curing agent, i.e., maleopimaric acid, and a two-component epoxy consisting of an E51-type epoxy and a solid phenolic epoxy to form a bio-sourced green matrix resin. The bio-content of the final epoxy system was about $40 \%$ by weight. For the composites with $57 \%$ carbon fiber volume fraction, the overall green content was around $12 \%$. The maleopimaric acid was initially developed by the Ningbo Institute of Materials Technology and Engineering, Chinese Academy 
of Sciences [30], and was provided for the study. The physical and chemical properties of the resin system are listed in Table 1.

Table 1. Physical and chemical properties of the resin system.

\begin{tabular}{ccc}
\hline Density, $\mathrm{g} / \mathrm{cm}^{2}$ & Gel Time at $120{ }^{\circ} \mathrm{C}, \mathrm{s}$ & $\begin{array}{c}\text { Peak Exothermic Temperature (Tp) under } 10^{\circ} \mathrm{C} / \mathrm{min} \\
\text { Heating Rate, }{ }^{\circ} \mathrm{C}\end{array}$ \\
\hline 1.18 & 500 & 164 \\
\hline
\end{tabular}

The apparent viscosity was performed on a cone plate viscometer (CAP2000+, Brookfield, Middleborough, MA, USA) with 6th rotation spider at a rotation rate of 300 RPM and a shear rate of $1000 \mathrm{~s}^{-1}$.

Figure 1 shows the curves of viscosity-temperature. In the temperature range of $90-150{ }^{\circ} \mathrm{C}$ the viscosity is just below $2000 \mathrm{mPa}$.s, which is suitable for glue film infiltrating the firmer. In the range of $60-70^{\circ} \mathrm{C}$, the viscosity is in the range of $20,000-10,000 \mathrm{mPa} . \mathrm{s}$, which is very good fit for adhesive film preparation.

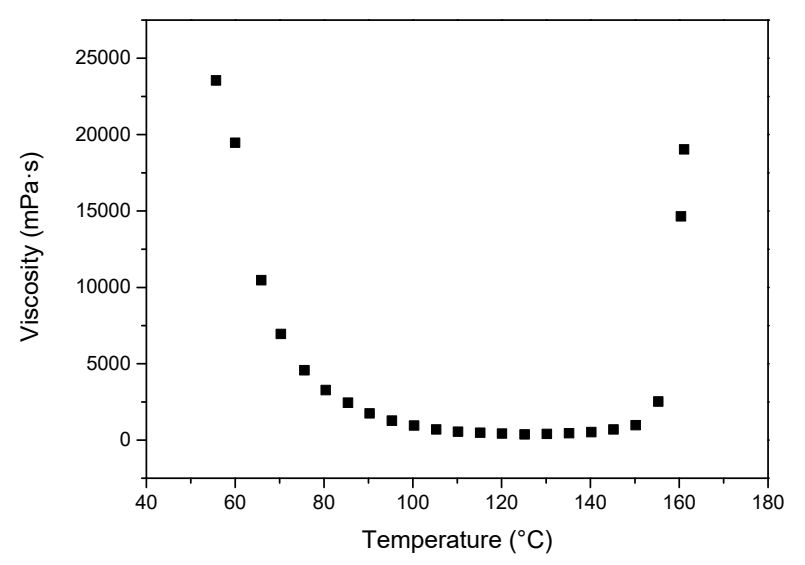

Figure 1. Viscosity-temperature curves of the resin system.

The high temperature epoxy resin was then cured at $180^{\circ} \mathrm{C}$ for $3 \mathrm{~h}$ to produce a cast bar for dynamic mechanical analysis (DMA242E, Netzsch Instruments, Selb, Germany). The rectangular bar of $50 \mathrm{~mm} \times 10.2 \mathrm{~mm} \times 3.1 \mathrm{~mm}$ was placed on a three-point bending clamp, and tested at an oscillation frequency of $2 \mathrm{~Hz}$, an amplitude of $10 \mu \mathrm{m}$, and a heating rate of $3^{\circ} \mathrm{C} \mathrm{min}^{-1}$. As shown in Figure 2, the cast bar specimen shows a single peak at $238^{\circ} \mathrm{C}$, indicating its glass transition temperature, $T_{\mathrm{g}}$.

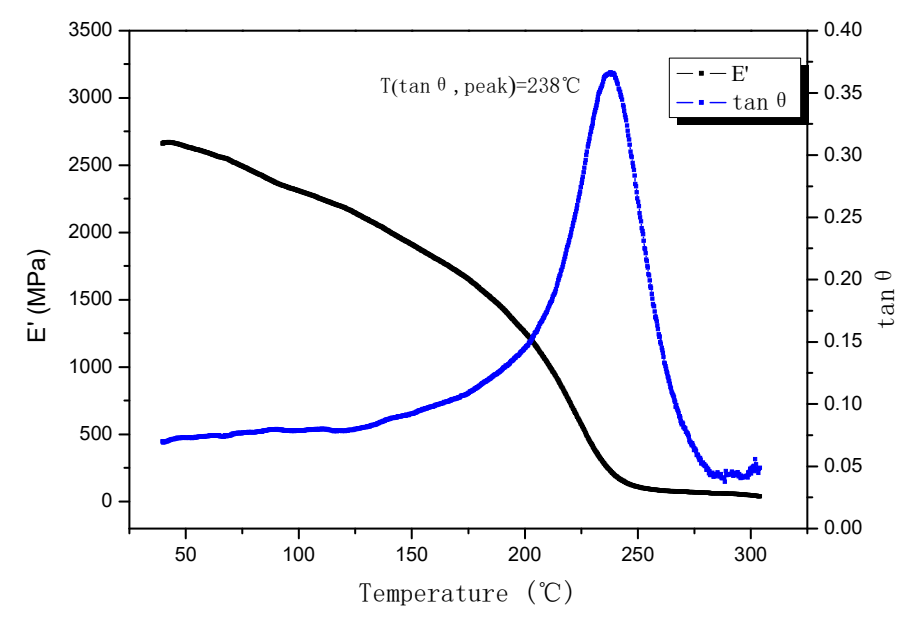

Figure 2. Dynamic mechanical test curves of the rosin-sourced epoxy cast bar. 
A commercial T700-grade carbon fiber SYT49S was chosen as reinforcement material for production of the green composites, Table 2, supplier Jiangsu Tianniao Hi-Tech Co., Ltd. (Wuxi, Jiangsu). The prepreg produced (Table 3) shows a resin weight fraction of $37.2 \mathrm{wt} \%$ and an areal density of $223.4 \mathrm{~g} / \mathrm{m}^{2}$. The nominal thickness of the prepreg was $0.14 \mathrm{~mm}$.

Table 2. Technical data of SYT49S, 12K, T700-grade carbon fiber.

\begin{tabular}{cccccc}
\hline $\begin{array}{c}\text { Strength, } \\
\mathbf{M P a}\end{array}$ & $\begin{array}{c}\text { Modulus, } \\
\mathbf{G P a}\end{array}$ & $\begin{array}{c}\text { Elongation at } \\
\text { Break, } \%\end{array}$ & $\begin{array}{c}\text { Linear Density, } \\
\mathbf{g} / \mathbf{k m}\end{array}$ & $\begin{array}{c}\text { Density, } \\
\mathbf{g} / \mathbf{c m}^{\mathbf{3}}\end{array}$ & $\begin{array}{c}\text { Diameter, } \\
\boldsymbol{\mu m}\end{array}$ \\
\hline 4900 & 230 & 2.1 & 800 & 1.79 & 7 \\
\hline
\end{tabular}

Table 3. Physical property of high temperature rosin-sourced epoxy/UN-SYT49S prepreg.

\begin{tabular}{cccc}
\hline Area Density, $\mathrm{g} / \mathrm{m}^{2}$ & Resin Content, wt $\%$ & Areal Weight, $\mathrm{g} / \mathrm{m}^{\mathbf{2}}$ & Volatile Content, wt $\%$ \\
\hline 140 & 37.2 & 223.4 & 0.85 \\
\hline
\end{tabular}

A proprietary polyamide non-woven veil (NV) was used as the interleaf material, provided by $\mathrm{N}^{2} \mathrm{IC}$ New Materials Co. Ltd. (Ningbo, China). The nominal thickness and areal weight were $60 \mu \mathrm{m}$ and $26.4 \mathrm{~g} / \mathrm{m}^{2}$, respectively. The average diameter of the polyamide fiber was around $14 \mu \mathrm{m}$. Figure 3 shows the upper and lower surface SEM images of the nonwoven used. As seen, the polyamide fibres are randomly entangled and fusion-bonded to form a porous network structure. The bonded nodes are found on both surfaces. The diameter of the bonded nodes was approximately $0.45 \mathrm{~mm}$ with 0.9-1.5 mm nodal spacing. Due to the fusion bonding, the polyamide fibers at the node regions are sunken and parallel to the plane of the veil. In addition, many granular particles are found on one surface. The diameter of the particles was 30-100 $\mu \mathrm{m}$ and the space between each of them was around $0.7 \mathrm{~mm}$. Some particles coalesced as shown in Figure 4 where the sectional optical microscope image for a four-layer sample of the NVs is casted in epoxy resin. The fusion-bonded nodes and the particles can be easily distinguished.
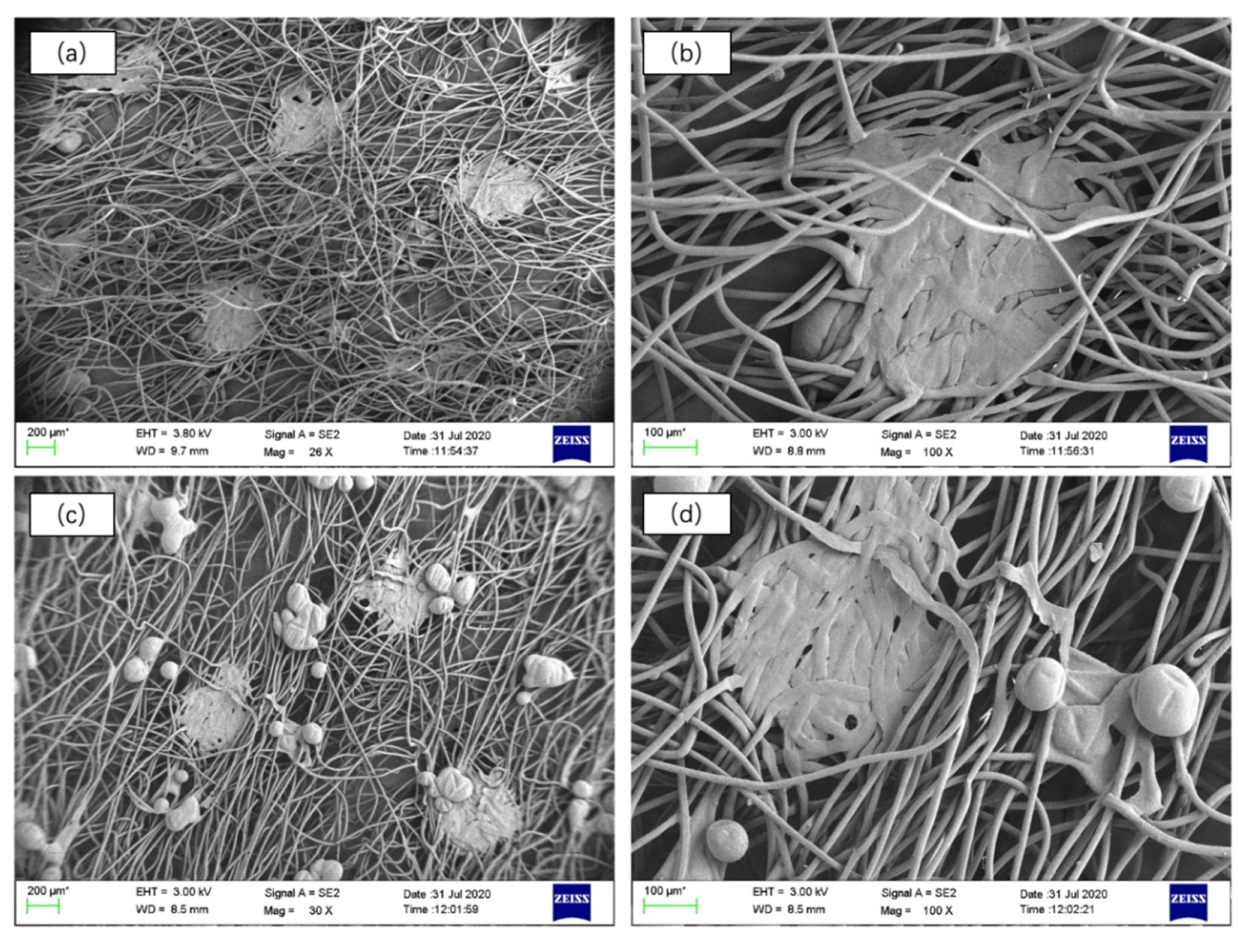

Figure 3. SEM images of polyamide nonwoven veil. $(\mathbf{a}, \mathbf{b})$ smooth side, $(\mathbf{c}, \mathbf{d})$ rough side. 


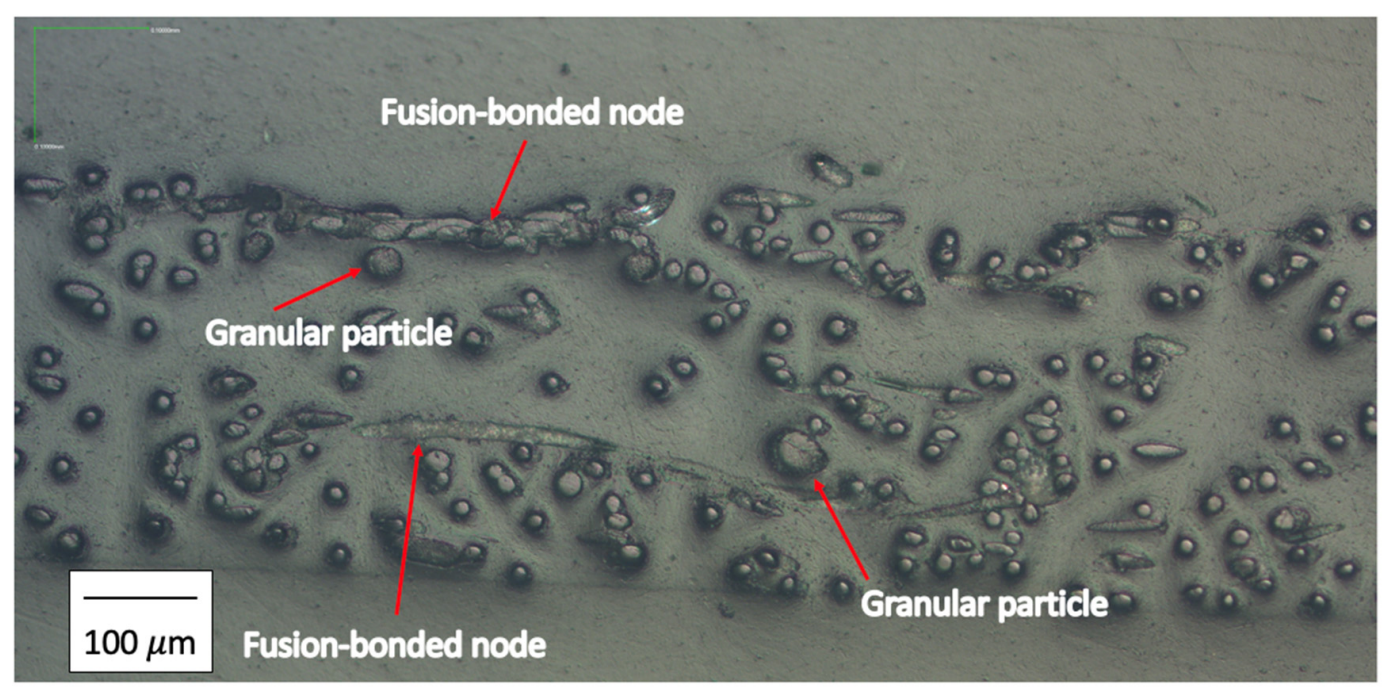

Figure 4. Sectional image of polyamide veil (four layers).

\subsection{Fabrication of Composite Laminates}

Vacuum bag assisted compression molding was used to manufacture the composite laminates. The prepregs were cut into $295 \mathrm{~mm} \times 295 \mathrm{~mm}$ plies. Then the laminate performs were placed on the tool plate. Figure 5 shows a schematic of the manufacturing set-up. A rigid hollow steel mold with a $300 \mathrm{~mm} \times 300 \mathrm{~mm}$ inner area was used to fix the boundary of the specimens. A thick glass fiber reinforced PTFE film was placed on the top of performs to transfer the load from the hot platen to the laminate performs. The laminate performs were degassed in a vacuum bag under room temperature. After the pressure reached $0.09 \mathrm{MPa}$, the preforms were transferred to the hot press. Figure 6 illustrates the parameters of the curing procedure. Cured composite laminates were removed from the press and cooled to room temperature with a vacuum applied throughout the cycle.

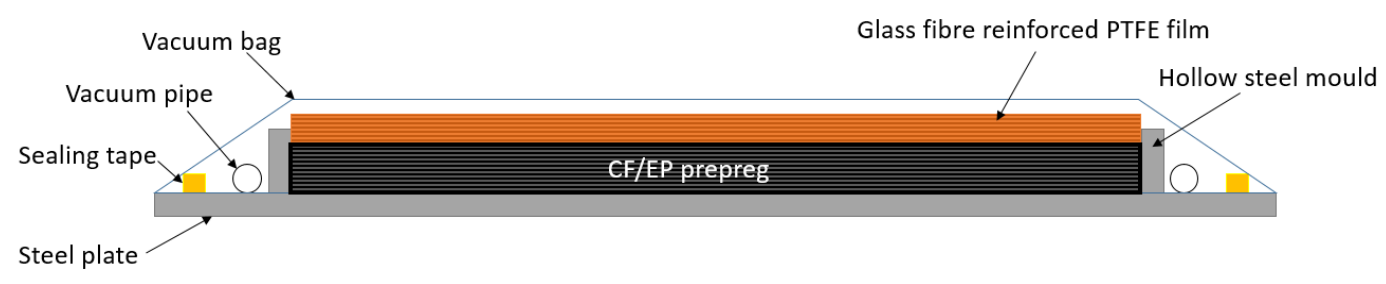

Figure 5. Schematic diagram of manufacturing set-up.

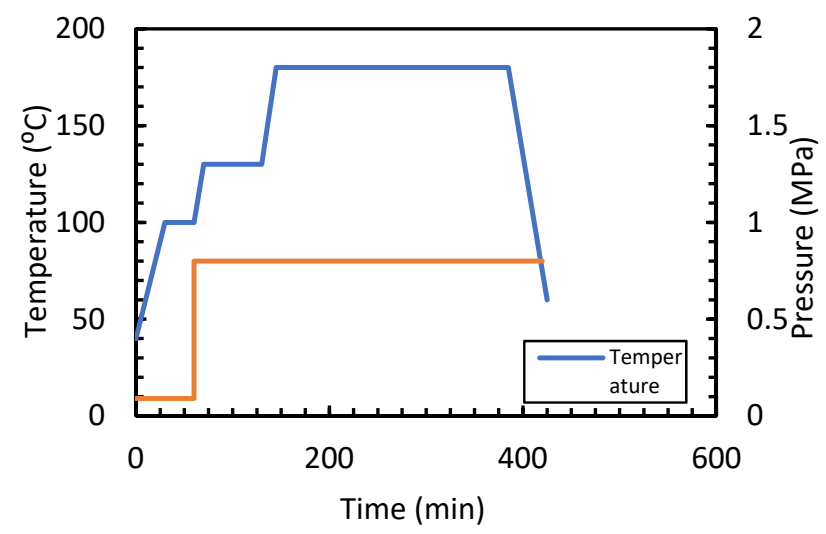

Figure 6. Curing procedure of the composite laminates. 


\subsection{Preparation of Test Specimens}

Table 4 shows characteristics of test specimens for the interlaminar fracture toughness study. Twenty four plies of the rosin-sourced epoxy matrix composites reinforced with unidirectional SYT49S carbon fibers were hand-stacked at $0^{\circ}$ orientation for Mode I and II interlaminar fracture toughness test, respectively. At the central layer, a $10 \mu \mathrm{m}$ thick release film $(100 \mathrm{~mm} \times 300 \mathrm{~mm})$ was placed at one end to simulate an initial crack for the control specimens, designed as $\mathrm{Control}^{-\mathrm{IFT}}$. For the interleaved specimens, the nonwoven veils were additionally placed between each carbon fiber ply, designed as NVIC-IFT.

Table 4. Characteristics of specimens for interlaminar toughness study.

\begin{tabular}{ccccc}
\hline Specimen & Lay-Up & Thickness $(\mathbf{m m})$ & Veil Mass Fraction (wt.\%) & Fibre Volume Fraction (Vf.\%) \\
\hline Control-IFT & \multirow{2}{*}[0]{$_{24}$} & $3.3 \pm 0.02$ & - & $56.7 \pm 0.32$ \\
NVIC $^{-I F T}$ & $3.9 \pm 0.01$ & $12.31 \pm 0.15 \%$ & $48.1 \pm 0.18$ \\
\hline
\end{tabular}

For drop-weight impact and compression after impact (CAI) study, the stacking sequence of laminate was $[+45 / 0 /-45 / 90]_{4 s}$. The laminate specimens were fully interleaved with the nonwoven veils between each carbon fiber ply, and one top of the specimens as the impact side was also covered with a nonwoven veil layer, designed as NVIC-CAI. Table 5 shows the characteristics of the test specimens for the CAI study.

Table 5. Characteristics of specimens for CAI study.

\begin{tabular}{ccccc}
\hline Specimen & Lay-up & Thickness $(\mathbf{m m})$ & Veil Mass Fraction (wt.\%) & Fibre Volume Fraction (Vf.\%) \\
\hline Control-CAI $\left.^{2}{ }^{2}+/ 0 /-/ 90\right]_{4 s}$ & $4.38 \pm 0.02$ & $4.86 \pm 0.02$ & $12.44 \pm 0.38$ & $57.04 \pm 0.05$ \\
NVIC $^{-C A I}$ & & & - & $51.48 \pm 0.21$ \\
\hline
\end{tabular}

For mechanical property study, laminate specimens with different stacking sequences were used to match the requirement of ASTM standards. The nonwoven veils were also placed between each carbon fiber ply to manufacture the NVIC specimens. The characteristics of all test specimens are shown in Table 6. For interleaving the NVs, it should be noted that the rough side (with granular particles) is the downside.

Table 6. Characteristic of specimens for mechanical properties study.

\begin{tabular}{|c|c|c|c|c|c|}
\hline Specimen. & Lay-Up & Thickness (mm) & $\begin{array}{l}\text { Veil Mass Fraction } \\
\text { (wt.\%) }\end{array}$ & $\begin{array}{c}\text { Fiber Volume } \\
\text { Fraction (Vf.\%) }\end{array}$ & Test \\
\hline $\begin{array}{l}\text { Control }^{-\mathrm{T}} \\
\text { NVIC }^{-\mathrm{T}}\end{array}$ & {$[0]_{5}$} & $\begin{array}{c}0.7 \pm 0.01 \\
0.81 \pm 0.01\end{array}$ & $\begin{array}{c}- \\
11.24 \pm 0.1\end{array}$ & $\begin{array}{c}55.56 \pm 0.8 \\
48.28 \pm 0.53\end{array}$ & Tensile test \\
\hline $\begin{array}{l}\text { Control-FS }^{-F S} \\
\text { NVIC }^{-F S}\end{array}$ & {$[0]_{20}$} & $\begin{array}{l}2.69 \pm 0.01 \\
3.09 \pm 0.01\end{array}$ & $11.9 \pm 0.06$ & $\begin{array}{l}58.1 \pm 0.32 \\
50.7 \pm 0.13\end{array}$ & $\begin{array}{c}\text { Flexural and Interlaminar } \\
\text { shear strength test }\end{array}$ \\
\hline $\begin{array}{l}\text { Control }^{-\mathrm{C}} \\
\text { NVIC }^{-\mathrm{C}}\end{array}$ & {$[0 / 90]_{6}$} & $\begin{array}{c}1.6 \pm 0.01 \\
1.78 \pm 0.02\end{array}$ & $13.08 \pm 0.07$ & $\begin{array}{l}58.44 \pm 0.37 \\
52.67 \pm 0.58\end{array}$ & Compression (CLC) test \\
\hline
\end{tabular}

\subsection{Determination of Interlaminar Fracture Toughness}

The interlaminar fracture toughness was determined by Mode I and Mode II tests, according to ASTM D5228 and ASTM D7905 [31,32], respectively. Tests were conducted on an MTS E42 universal test machine with a $5 \mathrm{KN}$ load cell. The Double Cantilever Beam specimen was prepared for Mode I toughness test with dimensions: width $b=25 \mathrm{~mm}$, length $\mathrm{L}=180 \mathrm{~mm}$. In order to measure the delamination length during test, white water-based marking fluid was coated on one edge of the specimen. A $1 \mathrm{~mm}$ vertical scale was used for first $5 \mathrm{~mm}$ from the insert end and a $5 \mathrm{~mm}$ vertical scale was used for the remaining $45 \mathrm{~mm}$. The crosshead rate was set as $1 \mathrm{~mm} / \mathrm{min}$ for loading procedure and 
$10 \mathrm{~mm} / \mathrm{min}$ for the unloading procedure. The Mode-I energy release rate, $G_{I C}$ was obtained through modified beam theory (MBT) with the following governing Equation (1):

$$
G_{I c}=\frac{3 P \delta}{2 b(a+|\Delta|)}
$$

where $P$ is the load, $\delta$ is the corresponding loading displacement, $b$ is the specimen width, $a$ is the delamination length and $|\Delta|$ is a function of delamination length obtained by generating a least squares plot of the $C^{1 / 3}$. The initiation value $G_{I c-i n i}$ was calculated from the load point where the delamination began, and the propagation value $G_{I c-p r o p}$ was calculated from each record point during the delamination process.

The 3-point End Notch Flexure (ENF) test specimens were prepared for Mode II toughness test. In the pre-cracked region, three vertical compliance calibration lines were marked as 20,30 , and $40 \mathrm{~mm}$ from the tip of the insert.

Specimens were loaded under $0.5 \mathrm{~mm} / \mathrm{min}$ crosshead rates with a $100 \mathrm{~mm}$ span length. The unloading crosshead rate was set as $1 \mathrm{~mm} / \mathrm{min}$. The Mode-II interlaminar fracture toughness was determined by following Equation (2):

$$
G_{I I c}=G_{Q}=\frac{3 m P_{M a x}^{2} a_{0}^{2}}{2 B}
$$

where $G_{Q}$ is the candidate toughness, $P_{M a x}$ is the maximum force from fracture test, $a_{0}$ is the initial crack length $(30 \mathrm{~mm}), B$ is the specimen width and $\mathrm{m}$ is the slop CC coefficient, which was obtained through linear least squares linear regression analysis.

\subsection{Drop-Weight Impact and Compression after Impact Test}

According to ASTM D7136 [33], the drop-weight impact test was conducted using Instron CEAST 9340 drop tower system to determine the damage resistance of CFRP laminates. Three Control ${ }^{-C A I}$ specimens and three NVIC-CAI specimens were tested. The dimensions of the test specimen were width $b=100 \mathrm{~mm}$, length $\mathrm{L}=150$. Test specimens were fixed by toggle clamp on the fixture base. The specified ratio of impact energy to specimen thickness was set as $6.7 \mathrm{~J} / \mathrm{mm}$. The induced damage area was measured by C-Scan, using a MISTRAS UPK-T36 immersion system with a $5 \mathrm{MHz}$ transducer. Subsequently, one Control ${ }^{-\mathrm{CAI}}$ and one $\mathrm{NVIC}^{-\mathrm{CAI}}$ specimen was cut near the impact point to obtain the sectional delamination images. The compression test was carried out according to ASTM D7137 [34] for the rest of the specimens. Tests were conducted on an Instron hydraulic test machine with a $25 \mathrm{KN}$ load cell. The loading rate was set as $1.25 \mathrm{~mm} / \mathrm{min}$. Specimens were loaded until failure and the CAI strength was calculated.

\subsection{Mechanical Tests}

The mechanical tests included flexure, interlaminar shear strength, compression and tensile fracture. For each experiment, five control specimens and five NVIC specimens were tested. The flexural strength and elasticity bending modulus $\left(0^{\circ}\right)$ was determined under a 3-point bending followed by ASTM D790 [35]. The dimensions of the test specimen were width $b=12.7 \mathrm{~mm}$, length $\mathrm{L}=125 \mathrm{~mm}$. The span-thickness ratio was 1:32 (span length $=96 \mathrm{~mm}$ ) and the crosshead rate is set as $1 \mathrm{~mm} / \mathrm{min}$. The flexural strength and modulus were calculated by Equations (3) and (4), respectively.

$$
\begin{aligned}
& \sigma_{f}=\frac{3 P L}{2 b d^{2}} \\
& E_{B}=\frac{L^{3} m}{4 b d^{3}}
\end{aligned}
$$


where $\sigma_{f}$ is the flexural strength, $E_{B}$ is the elasticity bending modulus, $P$ is the peak load, $L$ is the support span $(96 \mathrm{~mm}), b$ is the width of specimen, $d$ is the depth of specimen and $\mathrm{m}$ is the slope of tangent to the initial straight-line portion of load-displacement curve.

The interlaminar shear strength $\left(0^{\circ}\right)$ was determined by the short beam test according to ASTM D2344 [36]. The dimensions of the specimens were $6 \mathrm{~mm}$ in width and $18 \mathrm{~mm}$ in length. A span-thickness ratio is 1:4. Test specimens were loaded under $1 \mathrm{~mm} / \mathrm{min}$ crosshead rate. The interlaminar shear strength is obtained as a short-beam strength as Equation (5).

$$
F^{s b s}=0.75 \times \frac{P_{m}}{b h}
$$

where $F^{s b s}$ is the short-beam strength, $P_{m}$ is the maximum load, $b$ is the specimen width, and $h$ is the specimen thickness.

The compression test followed ASTM D6641 [37] using a combined loading compression (CLC) test fixture. The dimensions of the specimen are $12 \mathrm{~mm}$ in width and $140 \mathrm{~mm}$ in length. The gauge length was $13 \mathrm{~mm}$ where the two strain gauges are bonded on both surfaces. The loading rate was set as $1.3 \mathrm{~mm} / \mathrm{min}$. The laminate compressive strength and modulus were obtained by Equations (6) and (7), respectively.

$$
\begin{gathered}
F^{c u}=\frac{P_{f}}{w h} \\
E_{c}=\frac{P_{2}-P_{1}}{\left(\varepsilon_{x 2}-\varepsilon_{x 1}\right) w h}
\end{gathered}
$$

where $F^{c u}$ is the compressive strength, $E_{c}$ is the compressive modulus, $v_{x y}^{c}$ is the compressive Poisson's ratio, $P_{f}$ is the peak load to failure, $\varepsilon_{x 2} / \varepsilon_{x 1}$ is the actual strain nearest the upper/lower end of strain rage used, $P_{2} / P_{1}$ is the load at $\varepsilon_{x 2} / \varepsilon_{x 1}, w$ is the specimen width and $h$ is the specimen length.

The tensile test $\left(0^{\circ}\right)$ followed ASTM D3039 [38]. The dimensions of specimens were $15 \mathrm{~mm}$ in width and $250 \mathrm{~mm}$ in length. Two strain gages were bonded at the central position to obtain the stain. Aluminium tabs with $1.5 \mathrm{~mm}$ thickness, $56 \mathrm{~mm}$ length and $15 \mathrm{~mm}$ width were bonded by an epoxy adhesive. The crosshead rate was set as $2 \mathrm{~mm} / \mathrm{min}$. Tensile strength and modulus are determined as follows (Equations (8) and (9)):

$$
\begin{gathered}
F^{t u}=\frac{P_{\max }}{A} \\
E^{\text {chord }}=\frac{\Delta \sigma}{\Delta \varepsilon}
\end{gathered}
$$

where, $F^{t u}$ is the tensile strength, $E^{\text {chord }}$ is the elasticity tensile chord modulus, $P_{\max }$ is the maximum load, $\mathrm{A}$ is the cross section area of specimen, $\Delta \sigma / \Delta \varepsilon$ is the difference between applied stress/strain.

\subsection{Scanning Electron Microscopy}

Scanning Electron Microscopy (SEM) was conducted using a Zeiss Sigma VP SEM to investigate the microstructure. Test specimens were coated with a $4 \mu \mathrm{m}$ thick gold layer through Leica EM SCD 500 Gold sputter before SEM observation.

\section{Results and Discussion}

\subsection{Interlaminar Fracture Toughness}

The typical Mode I load-displacement curves are shown in Figure 7a. Both test groups show a linear increase before cracking occurred. Compared with Control $^{-\mathrm{IFT}}$, higher loads and further displacements for NVIC ${ }^{-I F T}$ specimens were obtained to initiate the crack. During the crack propagation, the NVIC ${ }^{-I F T}$ specimens showed an obvious non-linear growth until the peak load was achieved. The maximum loads of NVIC ${ }^{-\mathrm{IFT}}$ were almost twice those of $\mathrm{Control}^{\mathrm{IFT}}$. As a result, the average Mode I 
interlaminar fracture toughness $G_{I C-i n i}$ and $G_{I C-p r o p}$ of NVIC-IFT increased from $116.2 \mathrm{~J} / \mathrm{m}^{2}$ to $241.4 \mathrm{~J} / \mathrm{m}^{2}$ and $227.51 \mathrm{~J} / \mathrm{m}^{2}$ to $509.22 \mathrm{~J} / \mathrm{m}^{2}$ respectively (Figure $7 \mathrm{~b}$ ). The typical R-curves show that the $G_{I C-p r o p}$ values of NVIC-IFT were higher than that of control at each recorded point (Figure 8). The $G_{I C}$ value increased with the growth of delamination length, especially for the NVIC ${ }^{-I F T}$ specimens.
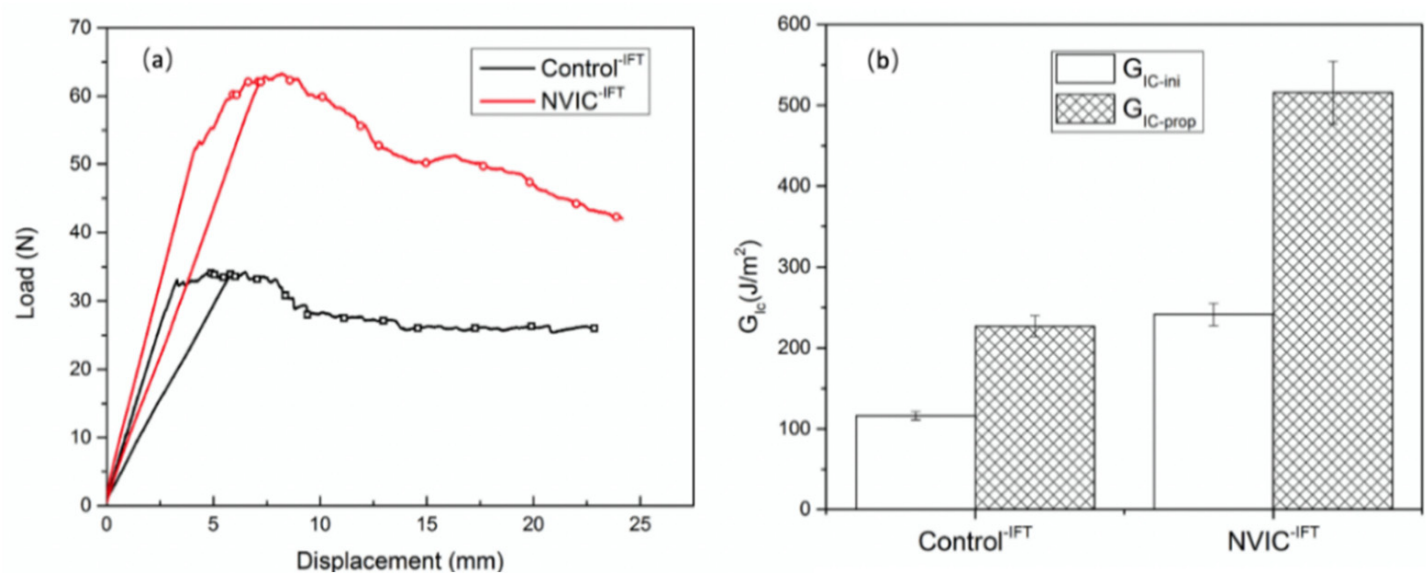

Figure 7. Results of the Mode I toughness test. (a) Typical DCB load-displacement curve, (b) Mode I interlaminar toughness.

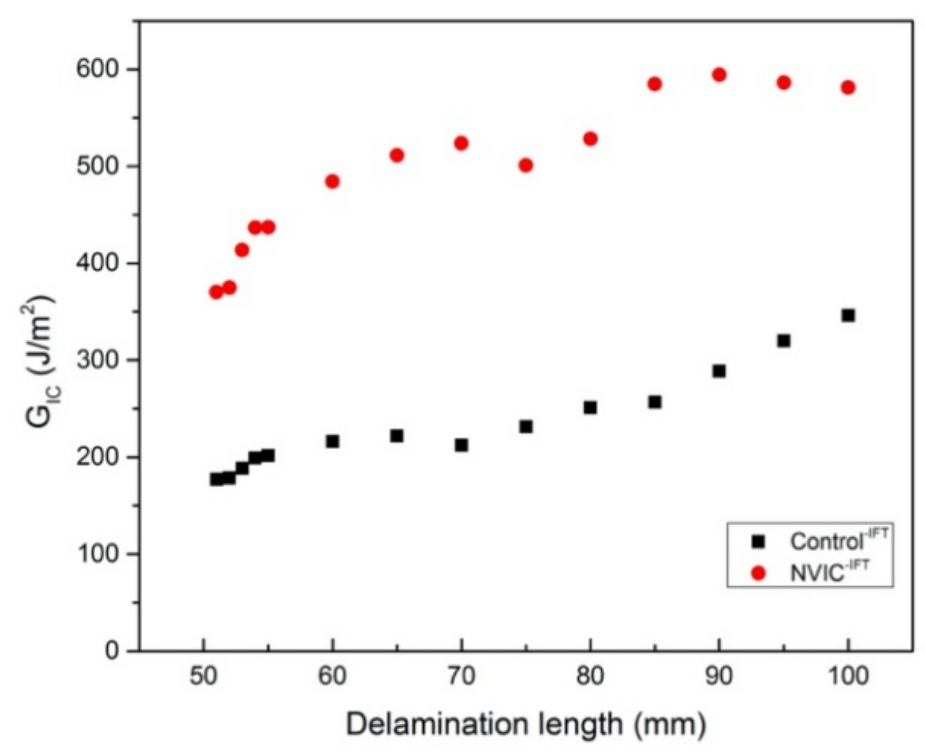

Figure 8. Typical R-curve for Mode I toughness test.

Figure 9a shows the Mode II load-displacement curves. Because the nonwoven veils are added between each carbon fiber ply, the slope of linear region of NVIC ${ }^{-I F T}$ specimens is slightly higher than that of the Control $^{-\mathrm{IFT}}$. The $\mathrm{Control}^{-\mathrm{IFT}}$ showed linear elastic behaviour up to $820 \mathrm{~N}$ peak load at $2.98 \mathrm{~mm}$ displacement, after which it drops sharply to $418 \mathrm{~N}$ accompanied by a sudden fracture. In contrast, the NVIC ${ }^{-\mathrm{IFT}}$ demonstrated a quasi-ductile fracture at $3.25 \mathrm{~mm}$ with a $1038 \mathrm{~N}$ peak load. Then the load dropped slowly and silently to $812 \mathrm{~N}$. The existence of nonwoven veils interlayers not only delayed the initiation of Mode II cracks but also increased the fracture energy for further crack growth. The average $G_{\text {IIC }}$ values of NVIC ${ }^{-I F T}$ were improved from $1064.3 \mathrm{~J} / \mathrm{m}^{2}$ to $1510.8 \mathrm{~J} / \mathrm{m}^{2}$ (Figure $9 \mathrm{~b}$ ). The discussion of Mode I and II toughening mechanisms will be provided in following section. 


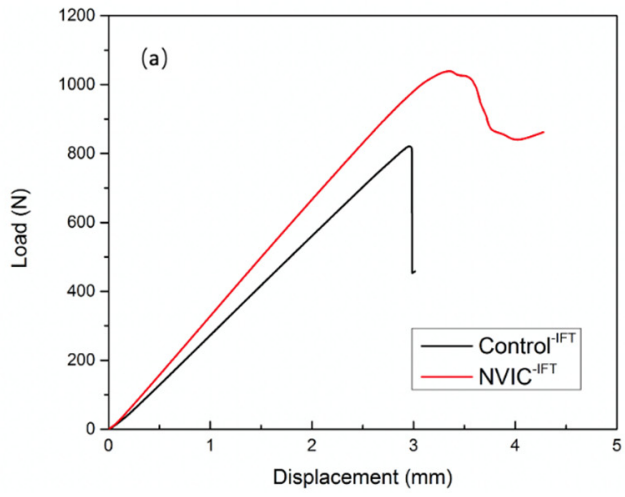

Figure 9. Results of the Mode II toughness test. interlaminar toughness.

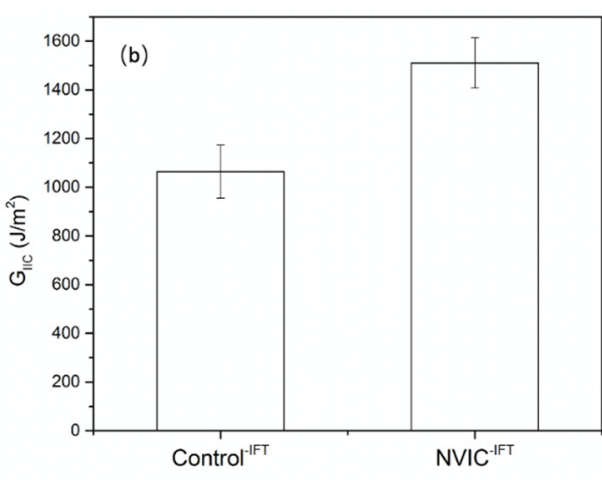

(a) ENF load-displacement curve, (b) Mode II

\subsection{Toughening Mechanisms}

According to the plane and side observation at delamination area (Figure 10a and Figure 13a), the Mode I delamination clearly occurs inside the polyamide/epoxy interlayer. It indicates that the Mode I delamination is dominated by the cohesive failure of the interlayer. Figure 11 shows the polyamide fiber failure of NVIC ${ }^{-\mathrm{IFT}}$ during a Mode I toughness test. For both sides, the polyamide fibers are gradually pulled out from the interlayer because of the interpenetrating network formed by epoxy matrix and non-woven veils, i.e., the polyamide fiber directions change from parallel to perpendicular to the carbon fiber plies. This process includes the fiber debonding, bridge and breakage, which leads to the fracture energy consumption. The SEM images of Mode I fracture surfaces are shown in Figure 12. Large numbers of fiber pull-out and breakage are evident at both sides of the fracture surfaces. The fusion-bond nodes are split, which also indicates that the cohesive strength of the fusion-bond node is lower than the bond strength between polyamide fibers and the epoxy matrix. In addition, the granular particles cannot be found either, but instead are regular distributed holes on the lower fracture surface (Figure 12a,b). Compared with the smooth fracture surface near these holes, the surfaces of the holes are rougher. Polyamide fibers, which are initially contacted with the granular particles, are pulled-out or broken and covered by the rough particles. Similar areas can also be found on the upper fracture surface (Figure 12c,d). It is considered that the granules have been split during the delamination process. The current study cannot demonstrate whether these particles have negative effects on Mode I toughness improvement. We will explore this in further investigations.
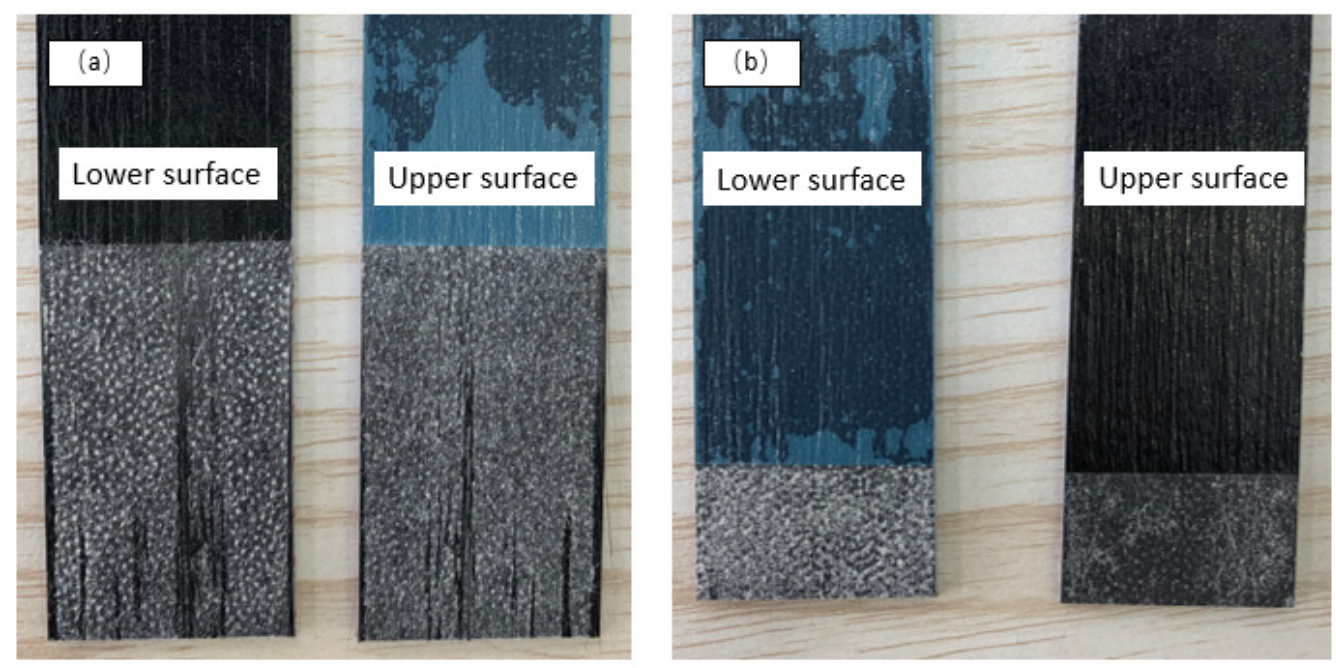

Figure 10. Plane view of fracture surfaces of NVIC ${ }^{- \text {ILT }}$. (a) Mode I, (b) Mode II. 

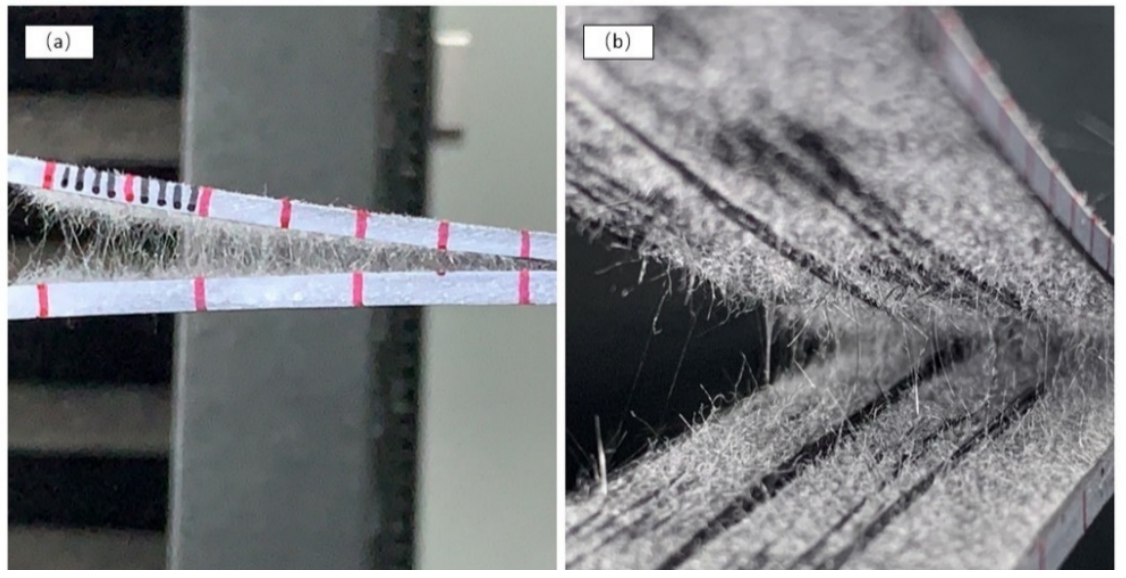

Figure 11. Failure mode of NVIC ${ }^{-I L T}$ in DCB test. (a) side view, (b) through open mouth.
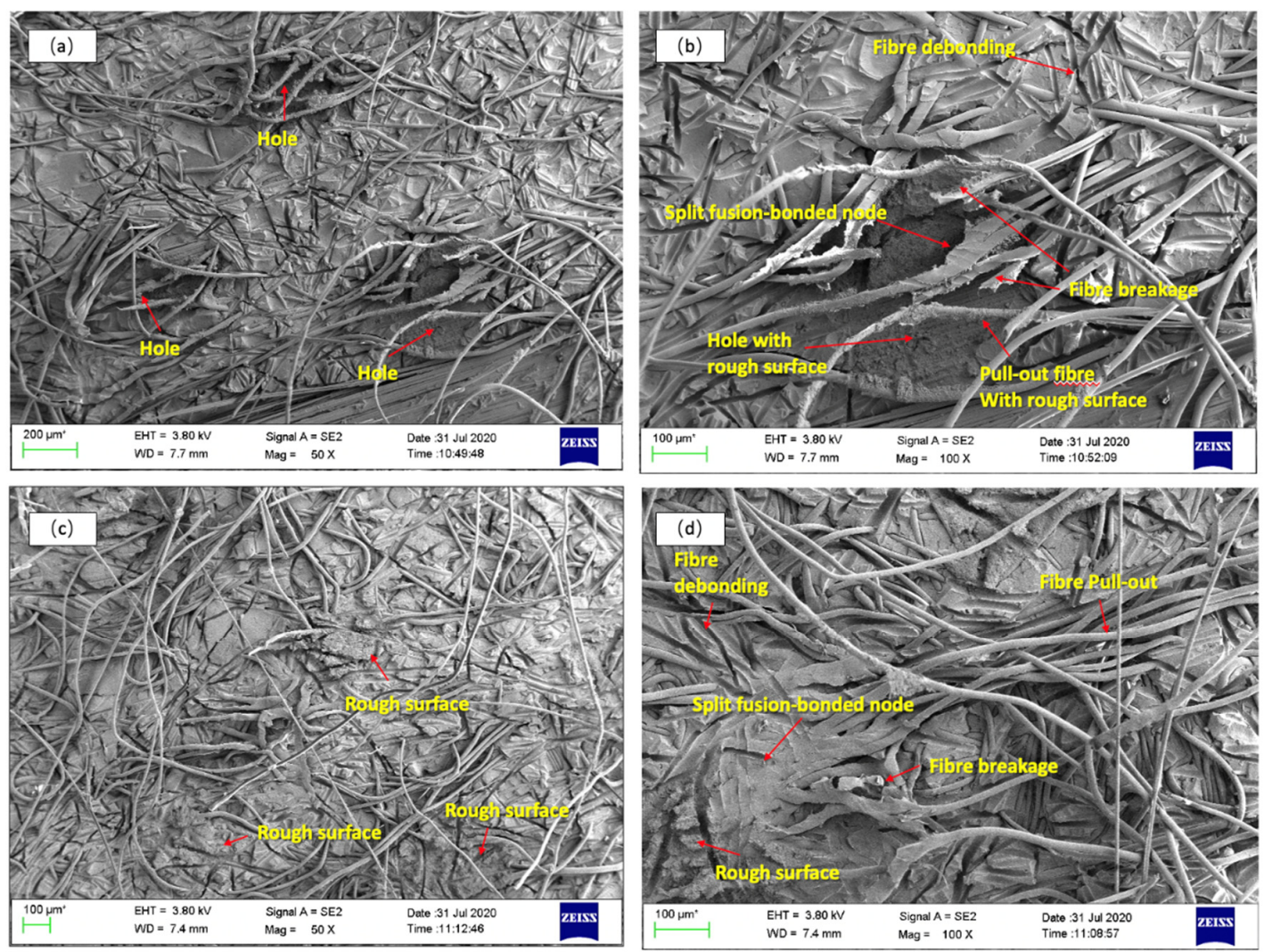

Figure 12. SEM images of fracture surface. $(\mathbf{a}, \mathbf{b})$ lower surface, $(\mathbf{c}, \mathbf{d})$ upper surface.

Figure 10b shows two Mode II fracture surfaces. The density of polyamide fibers on the lower surface is much higher than that of the upper surface. A closer section image at the crack region (Figure 13b) shows fractures at the CF/veils interface as well as the interlayer. SEM images of Mode II fracture surface show (carbon) fiber interface failure and polyamide fiber pull-out at both surfaces (Figure 14). Taking a closer inspection, complete fusion-bond nodes can be recognized, which are partly embedded into the lower fracture surface. Around the nodes, fiber pull-out and broken polyamide fibers resemble exposed plant roots. Granules cannot be found on the fracture surface and are probably concealed under the carbon fiber interface. Partially rough areas can be found near the exposed fusion-bonded nodes, which indicate that these particles were split during the Mode II delamination process. Thus, it is suggested that the cohesive failure occurs at the fusion-bond nodes and granules nearby, while the adhesive failure takes place at the polyamide/epoxy interpenetrating 
region. The Mode II delamination mostly occurs at the interface between the interlayer and CF ply with a small part transferred in the interlayer, i.e., the interlaminar shear strength of the interlayer is comparatively higher than the interfacial shear strength between the carbon fiber layer and the interlayer. Cracks propagate along the upper $\mathrm{CF} /$ veils interface and are reflected at the fusion-bonded nodes, with micro-interfacial failure, fiber pull-out and breakage are the major mechanisms for Mode II toughness improvement.
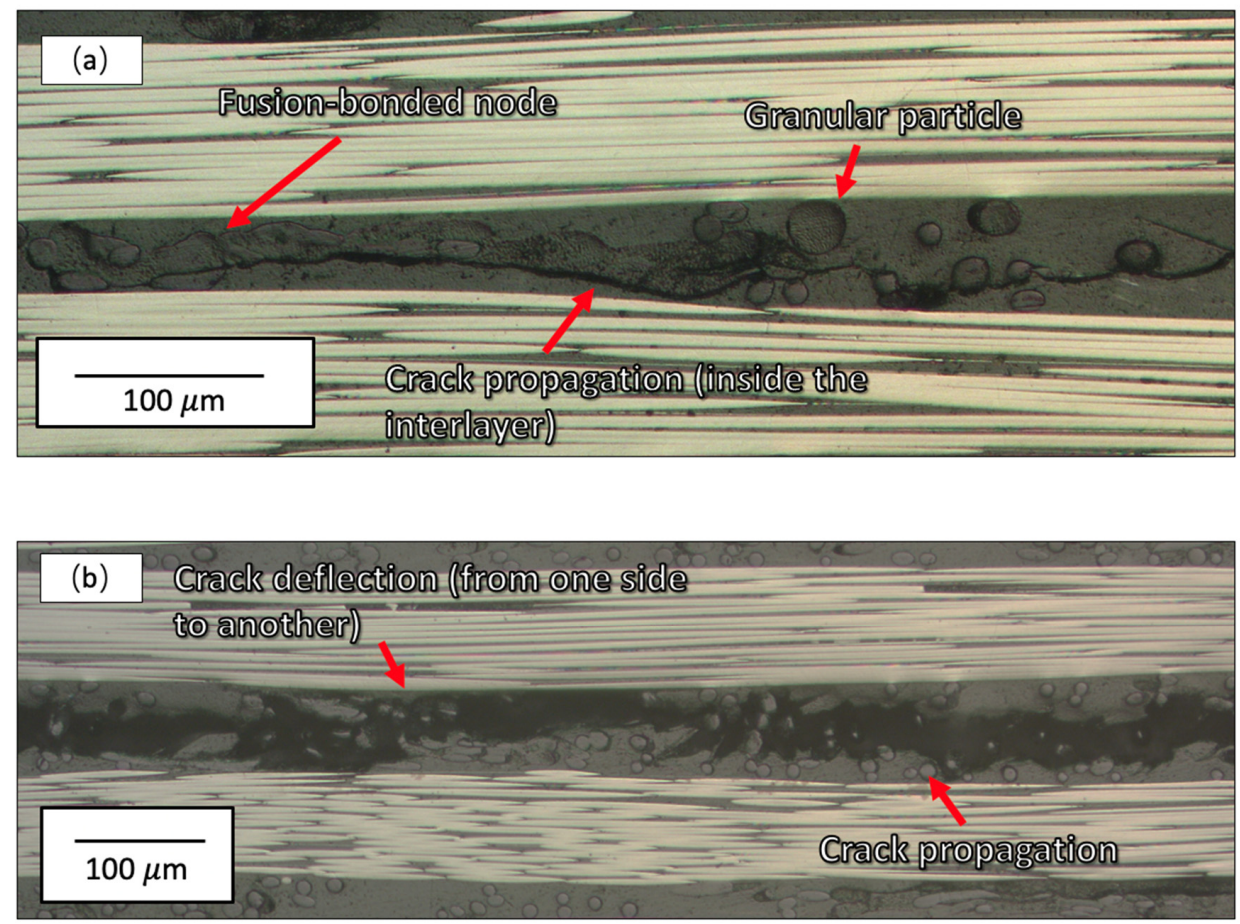

Figure 13. Optical observation of crack growth mode. (a) Mode I, (b) Mode II.
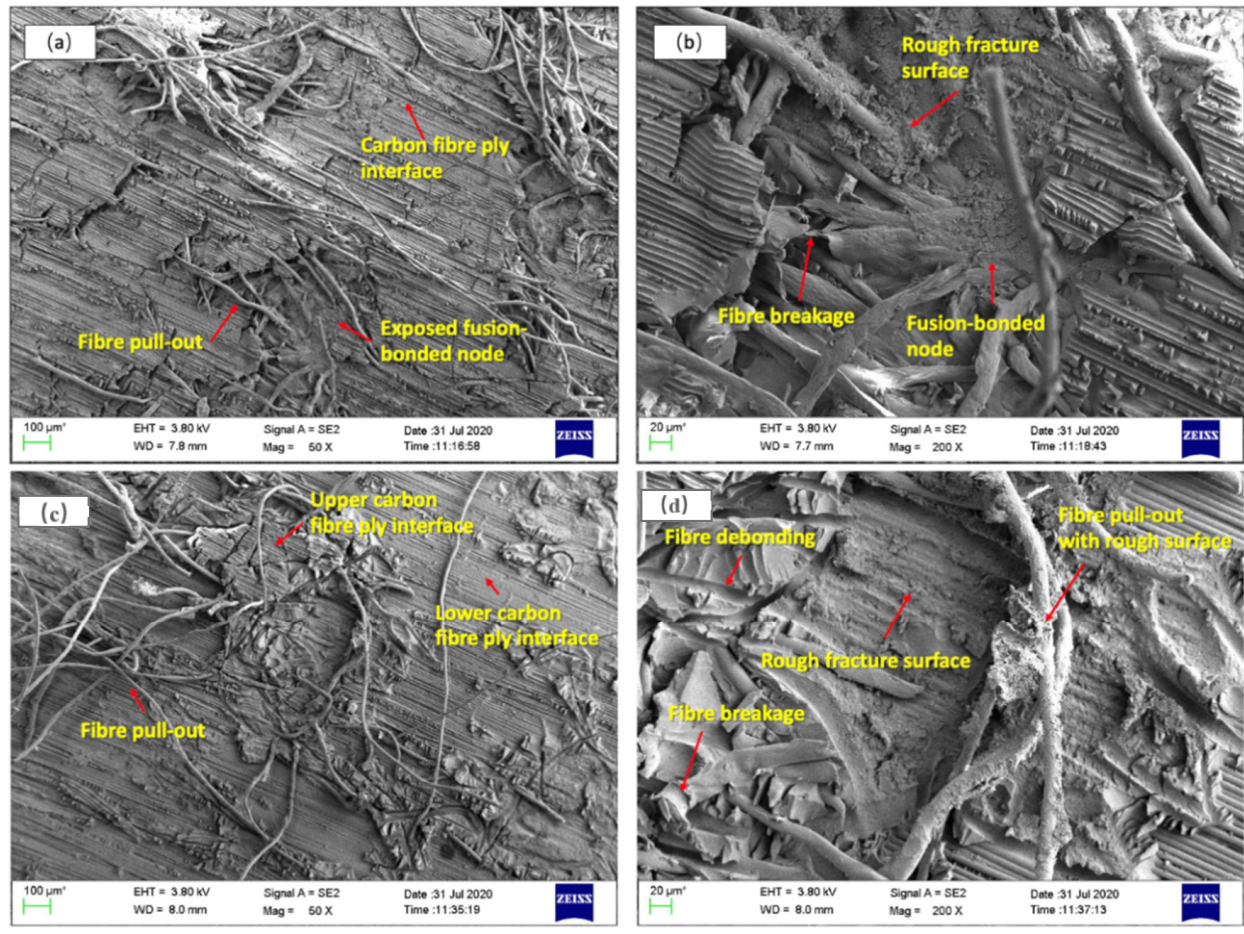

Figure 14. SEM images of Mode II fracture surface. (a,b) Lower surface, $(\mathbf{c}, \mathbf{d})$ upper surface. 


\subsection{Drop-Weight Impact and Residual Compression after Impact Strength}

The typical time histories of applied force during impact test are presented in Figure 15. The ratio of impact energy to specimen thickness is set as $6.7 \mathrm{~J} / \mathrm{mm}$. Both curves show that the peak force was generated around $2 \mathrm{~ms}$. The peak impact force acting on NVIC ${ }^{-\mathrm{CAI}}$ is around $2000 \mathrm{~N}$ higher than that of the Control ${ }^{-C A I}$. Table 7 shows the typical ultrasonic images of impacted specimens by using UTwin software. According to the images, the delamination area of Control-CAI was around $20.9 \%$. In contrast, the NVIC-CAI showed a significant improvement of impact resistance, as the delamination area was reduced to $11.33 \%$.

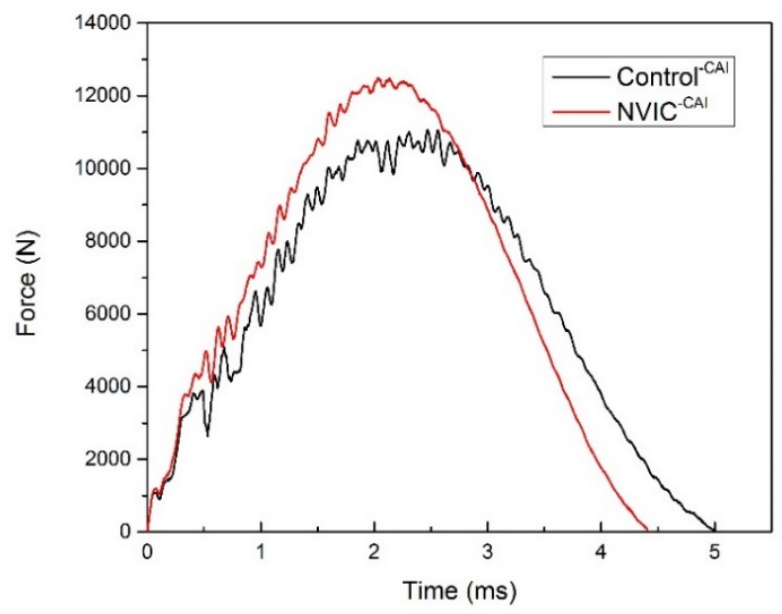

Figure 15. Time histories of the applied force during impact test.

Table 7. Characteristics of impact damage area.

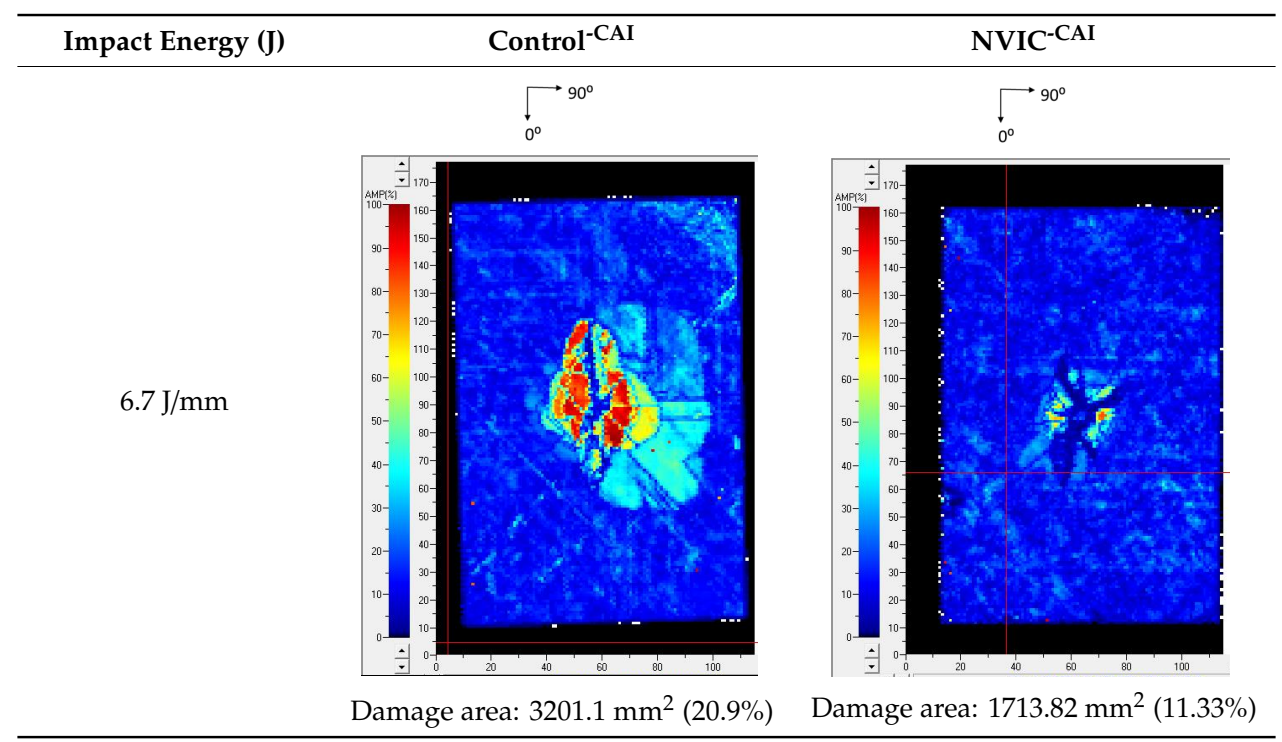

Figure 16a shows the compressive load-displacement curve for impacted specimens. The Control-CAI fails under $61.77 \mathrm{KN}$ with $1.21 \mathrm{~mm}$ crosshead displacement. Compared with the control specimen, the failure load of $\mathrm{NVIC}^{-\mathrm{CAI}}$ increased from $61.77 \mathrm{KN}$ to $92.64 \mathrm{KN}$ with further crosshead displacement $(1.55 \mathrm{~mm})$. Although the thickness of NVIC laminate was increased from $4.4 \mathrm{~mm}$ to $4.8 \mathrm{~mm}$ (Table 5), the CAI strength of NVIC-CAI remained significantly improved from $143.7 \mathrm{MPa}$ to $191.4 \mathrm{MPa}$, which was approximately $36 \%$ higher than the Control $^{-\mathrm{CAI}}$ (Figure 16b). 

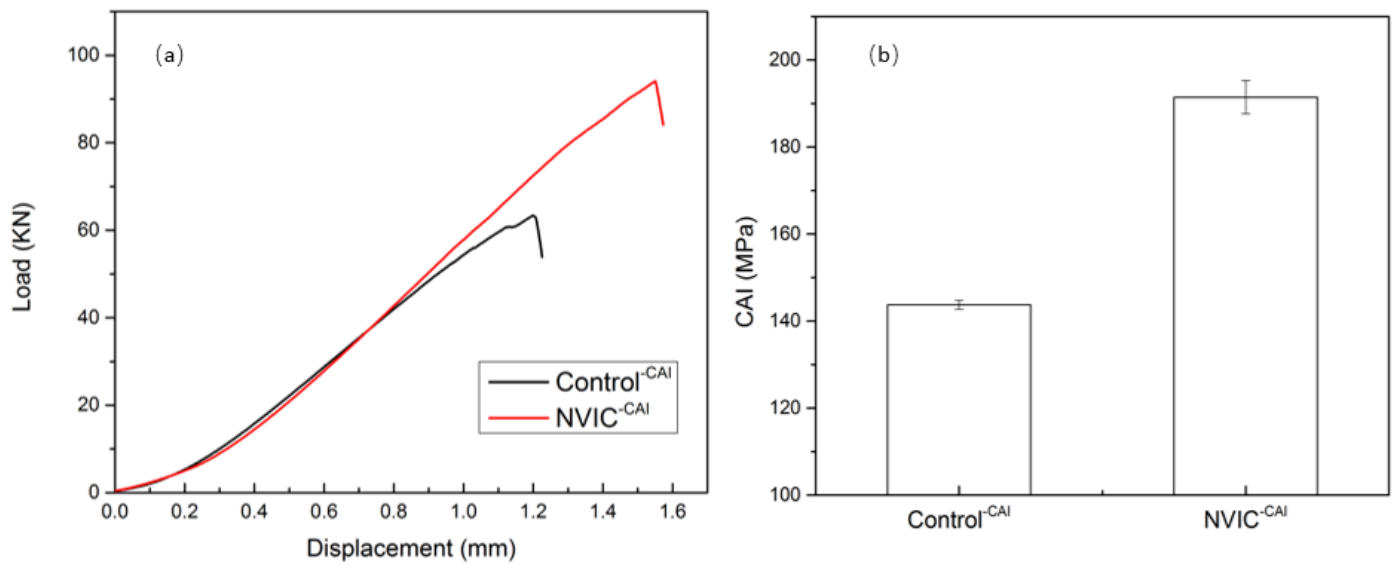

Figure 16. Results of the residual compression strength test. (a) Load-displacement curve, (b) residual compressive after impact strength.

Figure 17 shows microscope images of the damaged section near the impact point. For Control-CAI, many interlaminar delaminations were found, with the $45^{\circ}$ diagonal cracks passing through the carbon fiber layers (Figure 17a). For NVIC-CAI, the impact also caused many $45^{\circ}$ diagonal cracks inside the carbon fibre plies. However, closer inspection of the interlayer regions reveals that the delamination mostly happened in the interlayer with the cracks randomly deflecting from one interlayer/lamina interface to another (Figure 17b). As mentioned in Sections 3.1 and 3.2, the increase of CAI strength of NVIC $^{-C A I}$ is significant.

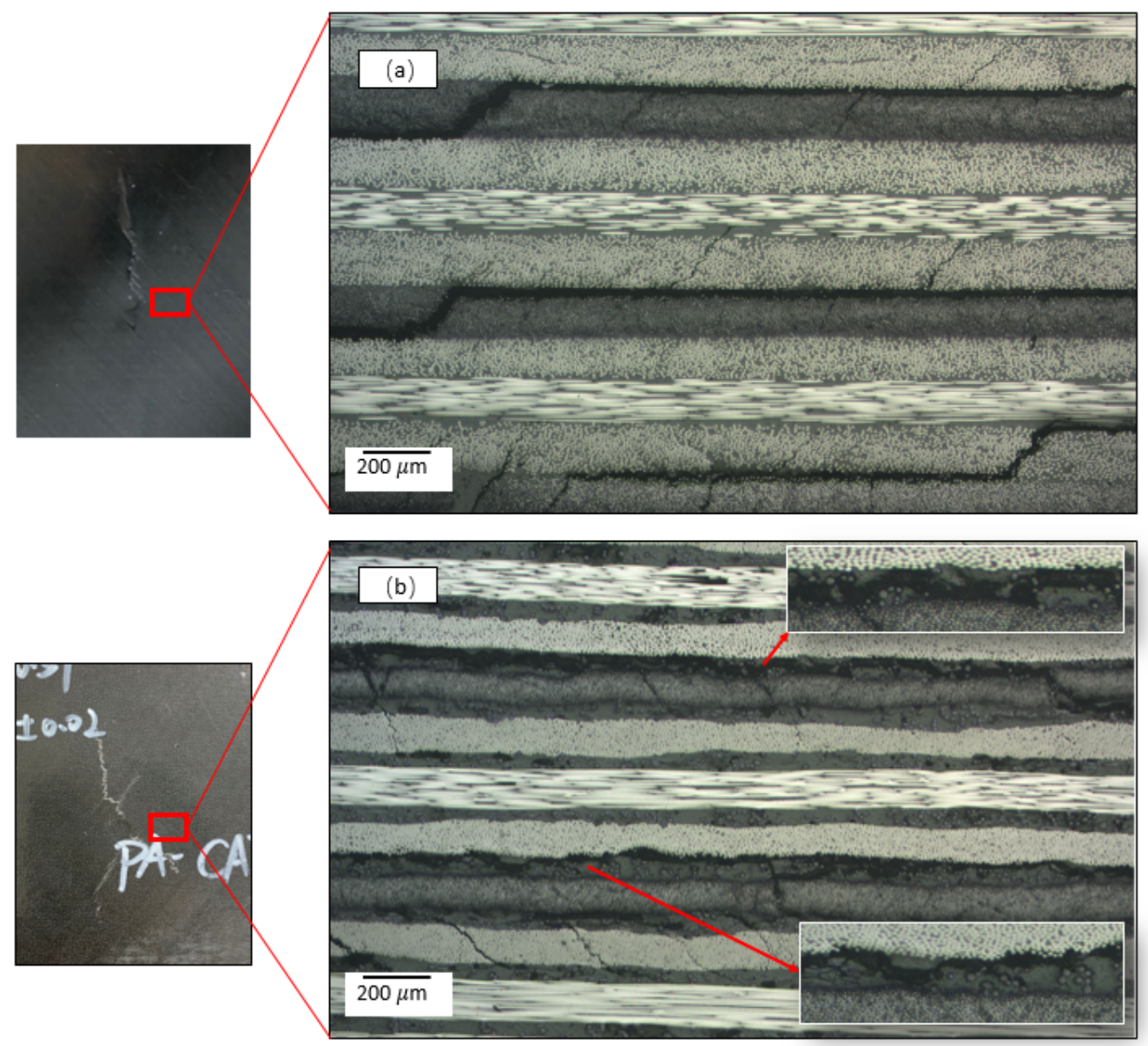

Figure 17. Sectional Observation Near Impact Head Area. (a) Control ${ }^{-\mathrm{CAI}}$, (b) NVIC ${ }^{-\mathrm{CAI}}$. 


\subsection{In-Plane Mechanical Properties}

The in-plane mechanical properties of test specimens are listed in Table 8, compared with the state-of-art counterparts as reference [39]. It should be noted that the compression strength and modulus of reference is in the $0^{\circ}$ fiber direction, which is generally higher than that of test specimens in this paper $\left(0 / 90^{\circ}\right)$. The overall mechanical properties of the green composites are comparable to the commercial petroleum-sourced products in the aerospace application.

Table 8. In-plane mechanical properties of test specimens and a commercial product.

\begin{tabular}{ccccc}
\hline Mechanical Property & UNIT & $\begin{array}{c}\text { Commercial Product (LY556/T700 } \\
\text { Toray 12K, Vf }=\mathbf{6 5 \%} \text {, UD) [39] }\end{array}$ & Control & NVIC \\
\hline Flexural strength $0^{\circ}$ & $\mathrm{MPa}$ & 1396.96 & $1187.3 \pm 46.4$ & $1049.2 \pm 39$ \\
Flexural modulus $0^{\circ}$ & $\mathrm{GPa}$ & 104.16 & $104 \pm 2.8$ & $93 \pm 1.4$ \\
Interlaminar shear strength & $\mathrm{MPa}$ & 57.83 & $73 \pm 0.2$ & $66.2 \pm 1$ \\
Tensile strength $0^{\circ}$ & $\mathrm{MPa}$ & 1235.70 & $2121.9 \pm 77.2$ & $1821.6 \pm 47.9$ \\
Tensile modulus $0^{\circ}$ & $\mathrm{GPa}$ & 134.58 & $130.1 \pm 2.8$ & $115.6 \pm 11.1$ \\
Compression strength $\left[0 / 90^{\circ}\right]$ & $\mathrm{MPa}$ & $674.7\left(0^{\circ}\right)$ & $469.3 \pm 22.8$ & $428.6 \pm 26$ \\
Compression modulus $\left[0 / 90^{\circ}\right]$ & $\mathrm{GPa}$ & $153.72\left(0^{\circ}\right)$ & $66.8 \pm 5.1$ & $55.1 \pm 2.2$ \\
\hline
\end{tabular}

For green composite specimens, in the $0^{\circ}$ tensile test, because the tensile properties of CFRP laminates are generally controlled by the fiber properties, similar load-displacement curves are obtained for all test specimens (Figure 18a). With increasing strain, the curves start to zigzag due to the fiber/matrix debonding and the transverse matrix cracking. All specimens failed under similar peak loads (around $21 \mathrm{KN}$ ), with a brittle-explosive failure mode. However, because the polyamide veils increase the total thickness of composite laminates, this reduced the carbon fiber volume fraction and the tensile strength and modulus of $\mathrm{NVIC}^{-\mathrm{T}}$ was reduced by $14.2 \%$ and $11.1 \%$, respectively.
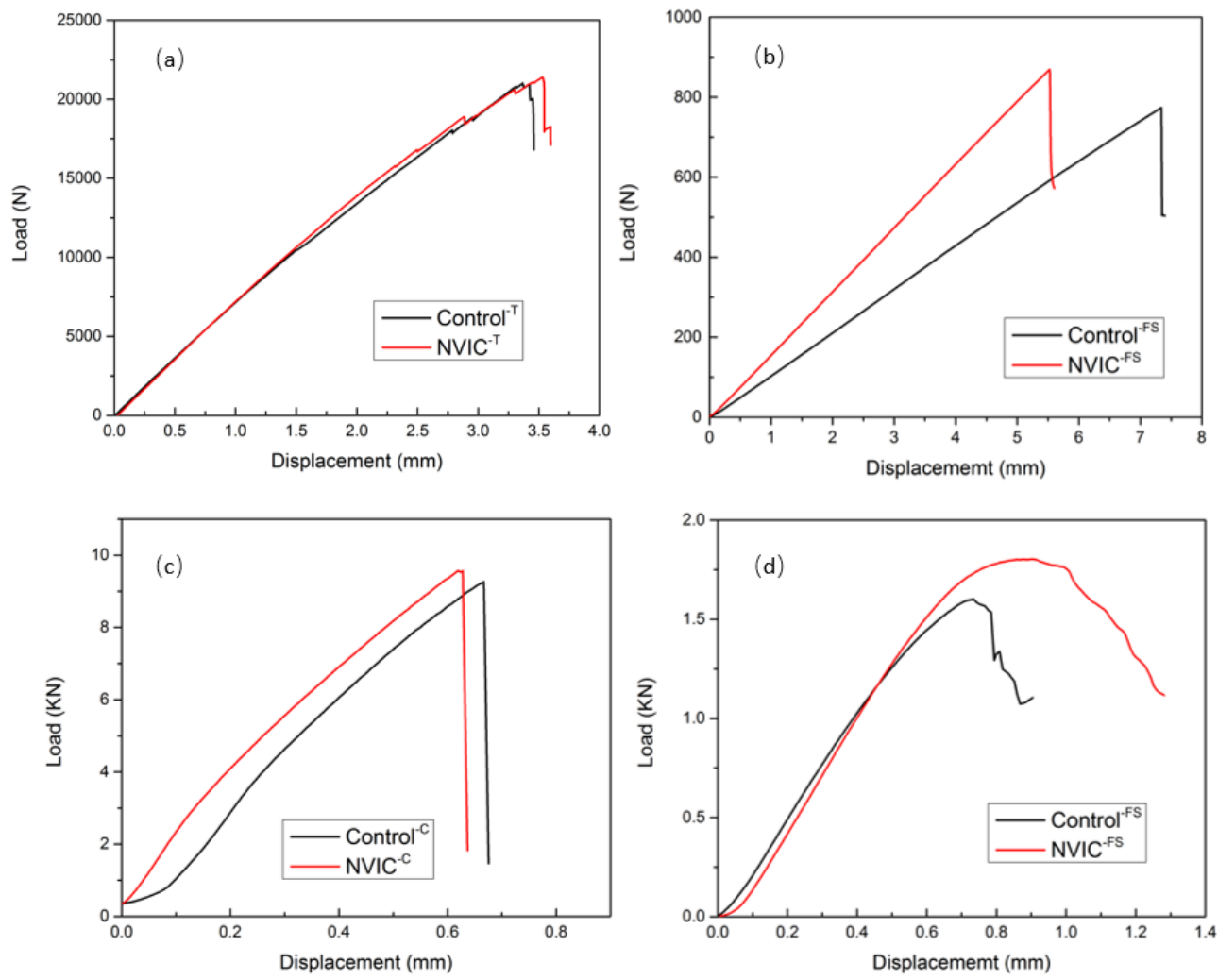

Figure 18. Load-displacement curves of in-plane mechanical test. (a) Tensile, (b) flexural, (c) compressive, and (d) interlaminar shear. 
In the flexural test, the final failure took place on the compression surface. The load-displacement curves (Figure 18b) indicate that the test specimens exhibit a linear elastic behaviour. Compared with the Control-SF, the NVIC ${ }^{-\mathrm{FS}}$ showed a relatively higher slope and failure load at shorter crosshead displacement. Figure $18 \mathrm{c}$ shows the typical failure mode from the compressive test. The final failure occurred within the gauge section, including delamination, fiber fracture and matrix cracking. The typical load-displacement curves showed no dramatic difference between the two test groups.

The interlaminar shear strength (ILSS) is one of the limiting design characteristics for composite laminates because of the anisotropic and relatively low mechanical properties in thickness direction. The final failure occurred at the one edge of the test specimen. Compared with the Control ${ }^{-\mathrm{FS}}$, the peak load of NVIC-FS was slightly improved (from 1.6 to $1.77 \mathrm{KN}$ ) with an obvious ductile stage (Figure 18d). However, the calculated ILSS of NVIC-FS was still reduced from 73.03 MPa to $66.23 \mathrm{MPa}(9.3 \%$ decrease) due to the increase of cross section area.

The overall decrease of in-plane mechanical properties with the addition of non-woven veils was attributed to the reduction of carbon fiber volume fraction of the toughened laminates. It should be noted that the compromise between toughness and mechanical properties is likely to be affected by the polyamide veil itself, i.e., areal weight and fiber architecture. In order to control the loss of mechanical properties, the content of the polyamide veil might be reduced, whilst retaining some toughness improvement. Our further investigations to explore these relations remain ongoing.

\section{Conclusions}

- We investigated the use of heat-bonded polyamide non-wovens as toughening interleaves in a green composite. Testing revealed useful improvements in toughness and CAI arising from changes in fracture mechanics with the incorporation of interleaves. Extensive study from fracture surfaces has yielded important information about crack propagation and the roles of the different features in the non-woven mat in controlling this.

- It is shown that the mechanical properties of the green composite system showed generally comparable performance with its commercial petroleum-sourced counterpart. Whilst the toughening effect was significant and demonstrable for the interleaved green composite, we also determined some reduction in static, in-plane properties due to the higher polymer ratio when interleaves were used. It is likely that some of this reduction could be mitigated by changing the stacking sequence and/or reducing the areal weight of the interleaves. Industrial application potential for a high temperature, toughened, "green composite" should be significant.

Author Contributions: Conceptualization, X.Y. and X.L.; methodology, D.H. and X.Z.; software, D.H. and X.Z.; validation, Z.Q. and L.H.; formal analysis, D.H. and X.Z.; investigation, D.H.; resources, X.Y. and X.Z.; data curation, D.H. and X.Z.; writing-original draft preparation, D.H.; writing-review and editing, D.H., X.Y. and C.R.; visualization, D.H.; supervision, X.Y., C.R. and X.L.; project administration, X.Y. and X.L.; funding acquisition, X.Y. and X.L. All authors have read and agreed to the published version of the manuscript.

Funding: This research was funded by Ningbo HTZ project of "New Carbon fibre Composite Technologies and Materials in Aerospace Functional Application", Shanghai Key Laboratory of Spacecraft Mechanism under Open Project Award No. 18DZ2272200, "Technology Helps Economy 2020" Program under Award No. SQ2020YFF0402997, NSFC and UKRI-EPSRC Cooperative Project "Green Recycling and re-manufacturing of Carbon fibre composites for a circular Economy (GRACE)", Ningbo S\&T bureau under Collaboration Project (Project code: 2017D10033), Ningbo Commonweal research program (2019C50027) and the Li Dak Sum Innovation Incubator Foundation of the University of Nottingham Ningbo China. The APC was funded by Li Dak Sum Innovation Incubator Foundation of the University of Nottingham Ningbo China.

Acknowledgments: The authors wish to gratefully acknowledge the funding and support of Ningbo HTZ project of "New Carbon fibre Composite Technologies and Materials in Aerospace Functional Application", Shanghai Key Laboratory of Spacecraft Mechanism under Open Project Award No. 18DZ2272200, “Technology Helps Economy 2020" Program under Award No. SQ2020YFF0402997, NSFC and UKRI-EPSRC Cooperative Project "Green Recycling And re-manufacturing of Carbon fibre composites for a circular Economy (GRACE)", Ningbo S\&T bureau under Collaboration Project (Project code: 2017D10033), Ningbo Commonweal research program (2019C50027) and especially the Li Dak Sum Innovation Incubator Foundation of the University of Nottingham Ningbo China for its generous funding. 
Conflicts of Interest: The authors declare no conflict of interest.

\section{References}

1. Darecki, M.; Edelstenne, C.; Enders, T.; Fernandez, E.; Hartman, P.; Herteman, J.-P.; Kerkloh, M.; King, I.; Ky, P.; Mathieu, M.; et al. Flightpath 2050 Europe's Vision for Aviation; Publications Office of the European Union: Luxembourg, 2011.

2. Liu, X.; Yi, X.; Zhu, J. Bio-based epoxies and composites as environmentally friendly alternative materials. In Thermosets: Structure, Properties and Applications; Guo, Q., Ed.; Elsevier: Amsterdam, The Netherlands, 2018; pp. 621-637. ISBN 9780081010211.

3. Yi, X.; Tserpes, K. Special issue "ECO-COMPASS: Ecological and multifunctional composites for application in aircraft interior and secondary structures". Aerospace 2019, 6, 17. [CrossRef]

4. Bachmann, J.; Yi, X.; Gong, H.; Martinez, X.; Bugeda, G.; Oller, S.; Tserpes, K.; Ramon, E.; Paris, C.; Moreira, P.; et al. Outlook on ecologically improved composites for aviation interior and secondary structures. CEAS Aeronaut. J. 2018, 9, 533-543. [CrossRef]

5. Yi, X.; Zhang, X.; Tong, J.; Xian, G. BIO-COMPOSITES Development of Bio-Composites for Green Aviation and Ground Vehicles. Sampe J. 2018, 16-26.

6. Zhang, X.F.; Wu, Y.Q.Q.G.; Wei, J.H.; Tong, J.F.; Yi, X.S. Curing kinetics and mechanical properties of bio-based composite using rosin-sourced anhydrides as curing agent for hot-melt prepreg. Sci. China Technol. Sci. 2017, 60, 1318-1331. [CrossRef]

7. Kumar, S.; Samal, S.K.; Mohanty, S.; Nayak, S.K. Study of curing kinetics of anhydride cured petroleum-based (DGEBA) epoxy resin and renewable resource based epoxidized soybean oil (ESO) systems catalyzed by 2-methylimidazole. Thermochim. Acta 2017, 654, 112-120. [CrossRef]

8. Hu, F.; Yadav, S.K.; La Scala, J.J.; Sadler, J.M.; Palmese, G.R. Preparation and Characterization of Fully Furan-Based Renewable Thermosetting Epoxy-Amine Systems. Macromol. Chem. Phys. 2015, 216, 1441-1446. [CrossRef]

9. Marotta, A.; Faggio, N.; Ambrogi, V.; Cerruti, P.; Gentile, G.; Mija, A. Curing Behavior and Properties of Sustainable Furan-Based Epoxy/Anhydride Resins. Biomacromolecules 2019, 20, 3831-3841. [CrossRef] [PubMed]

10. Wong, D.W.Y.; Lin, L.; McGrail, P.T.; Peijs, T.; Hogg, P.J. Improved fracture toughness of carbon fibre/epoxy composite laminates using dissolvable thermoplastic fibres. Compos. Part A Appl. Sci. Manuf. 2010, 41, 759-767. [CrossRef]

11. Van Velthem, P.; Ballout, W.; Daoust, D.; Sclavons, M.; Cordenier, F.; Henry, E.; Dumont, D.; Destoop, V.; Pardoen, T.; Bailly, C. A Influence of thermoplastic diffusion on morphology gradient and on delamination toughness of RTM-manufactured composites. Compos. Part A 2015, 72, 175-183. [CrossRef]

12. Hourston, D.J.; Lane, J.M. The toughening of epoxy resins with thermoplastics: 1. Trifunctional epoxy resin-polyetherimide blends. Polymer 1992, 33, 1379-1383. [CrossRef]

13. Yun, N.G.; Won, G.Y.; Kim, S.C. Toughening of carbon fiber/epoxy composite by inserting polysulfone film to form morphology spectrum. Polymer 2004, 45, 6953-6958. [CrossRef]

14. Sun, Z.; Xu, L.; Chen, Z.; Wang, Y.; Tusiime, R.; Cheng, C.; Zhou, S.; Liu, Y.; Yu, M.; Zhang, H. Enhancing the mechanical and thermal properties of epoxy resin via blending with thermoplastic polysulfone. Polymers 2019, 11, 461. [CrossRef] [PubMed]

15. Chen, H.; Su, C.; Huang, T.; Li, T. Investigation of the relationship between morphology and tribological properties of an epoxy resin based on tetraglycidyl $4,4^{\prime}$-diaminodiphenylmethane modified with polyetherimide oligomers. J. Appl. Polym. Sci. 2014, 131. [CrossRef]

16. Wu, Z.; Yi, X.; Wilkinson, A. Interlaminar fracture toughness of carbon fi bre/RTM6-2 composites toughened with thermoplastic-coated fabric reinforcement. Compos. Part B 2017, 130, 192-199. [CrossRef]

17. Zhang, J.; Guo, Q.; Fox, B.L. Study on thermoplastic-modified multifunctional epoxies: Influence of heating rate on cure behaviour and phase separation. Compos. Sci. Technol. 2009, 69, 1172-1179. [CrossRef]

18. Gan, W.; Yu, Y.; Wang, M.; Tao, Q.; Li, S. Viscoelastic Effects on the Phase Separation in ThermoplasticsModified Epoxy Resin. Macromol. Chem. Phys. 2003, 35, 7746-7751. [CrossRef] 
19. Aljarrah, M.T.; Abdelal, N.R. Improvement of the mode I interlaminar fracture toughness of carbon fiber composite reinforced with electrospun nylon nanofiber. Compos. Part B Eng. 2019, 165, 379-385. [CrossRef]

20. Zheng, N.; Huang, Y.; Liu, H.Y.; Gao, J.; Mai, Y.W. Improvement of interlaminar fracture toughness in carbon fiber/epoxy composites with carbon nanotubes/polysulfone interleaves. Compos. Sci. Technol. 2017, 140, 8-15. [CrossRef]

21. Zhou, H.; Du, X.; Liu, H.Y.; Zhou, H.; Zhang, Y.; Mai, Y.W. Delamination toughening of carbon fiber/epoxy laminates by hierarchical carbon nanotube-short carbon fiber interleaves. Compos. Sci. Technol. 2017, 140, 46-53. [CrossRef]

22. Hogg, P.J. Toughening of thermosetting composites with thermoplastic fibres. Mater. Sci. Eng. A 2005, 412, 97-103. [CrossRef]

23. Xu, F.; Yang, B.; Feng, L.; Huang, D.; Xia, M. Improved interlaminar fracture toughness and electrical conductivity of CFRPs with non-woven carbon tissue interleaves composed of fibers with different lengths. Polymers 2020, 12, 803. [CrossRef] [PubMed]

24. Ramirez, V.A.; Hogg, P.J.; Sampson, W.W. The influence of the nonwoven veil architectures on interlaminar fracture toughness of interleaved composites. Compos. Sci. Technol. 2015, 110, 103-110. [CrossRef]

25. Cheng, Q.; Fang, Z.; Yi, X.; An, X.; Tang, B.; Xu, Y. “ Ex Situ " Concept for Toughening the RTMable BMI Matrix Composites, Part I: Improving the Interlaminar Fracture Toughness. J. Appl. Polym. Sci. 2008, 109. [CrossRef]

26. Nasser, J.; Zhang, L.; Sodano, H. Aramid nanofiber interlayer for improved interlaminar properties of carbon fiber/epoxy composites. Compos. Part B Eng. 2020, 197, 108130. [CrossRef]

27. Yi, X.; Guo, M.; Liu, G.; Zhao, W.; Liu, L.; Cui, H. Composite conductive sheet, fabricating method and application thereof. European Patent EP2687364A1, 22 January 2014.

28. Hu, D.; Yi, X.; Jiang, M.; Li, G.; Cong, X.; Liu, X.; Rudd, C. Development of highly electrically conductive composites for aeronautical applications utilizing bi-functional composite interleaves. Aerosp. Sci. Technol. 2020, 98, 105669. [CrossRef]

29. Guo, M.; Yi, X.; Rudd, C.; Liu, X. Preparation of highly electrically conductive carbon-fiber composites with high interlaminar fracture toughness by using silver-plated interleaves. Compos. Sci. Technol. 2019, 176, 29-36. [CrossRef]

30. Liu, X.; Xin, W.; Zhang, J. Rosin-based acid anhydrides as alternatives to petrochemical curing agents. Green Chem. 2009, 11, 1018-1025. [CrossRef]

31. ASTM D5528-01 Standard Test Method for Mode I Interlaminar Fracture Toughness of Unidirectional Fiber-Reinforced Polymer Matrix Composites. Available online: https://www.astm.org/Standards/D5528 (accessed on 30 August 2020).

32. ASTM D7905 Standard Test Method for Mode II Interlaminar Fracture Toughness of Unidirectional Fiber-Reinforced Polymer Matrix Composites. Available online: https://www.astm.org/Standards/D7905.htm (accessed on 30 August 2020).

33. ASTM D7136/D7136M-12 Standard Test Method for Measuring the Damage Resistance of a Fiber-Reinforced Polymer Matrix Composite to a Drop-Weight Impact Event. Available online: https://www.astm.org/ Standards/D7136.htm (accessed on 30 August 2020).

34. ASTM D7137/D7137M-17 Standard Test Method for Compressive Residual Strength Properties of Damaged Polymer Matrix Composite Plates. Available online: https:/www.astm.org/Standards/D7137.htm (accessed on 30 August 2020).

35. ASTM D790-17 Standard Test Methods for Flexural Properties of Unreinforced and Reinforced Plastics and Electrical Insulating Materials. Available online: https://www.astm.org/Standards/D790 (accessed on 30 August 2020).

36. ASTM D2344/D2344M-16 Standard Test Method for Short-Beam Strength of Polymer Matrix Composite Materials and Their Laminates. Available online: https:/www.astm.org/Standards/D2344 (accessed on 30 August 2020).

37. ASTM D6641/D6641M-16e1 Standard Test Method for Compressive Properties of Polymer Matrix Composite Materials Using a Combined Loading Compression (CLC) Test Fixture. Available online: https://www.astm. org/Standards/D6641 (accessed on 30 August 2020). 
38. ASTM D3039/D3039M-17 Standard Test Method for Tensile Properties of Polymer Matrix Composite Materials. Available online: https://www.astm.org/Standards/D3039 (accessed on 30 August 2020).

39. Venkateshwar Reddy, C.; Ramesh Babu, P.; Ramnarayanan, R.; Das, D. Mechanical Characterization of Unidirectional Carbon and Glass/Epoxy Reinforced Composites for High Strength Applications. Mater. Today Proc. 2017, 4, 3166-3172. [CrossRef]

Publisher's Note: MDPI stays neutral with regard to jurisdictional claims in published maps and institutional affiliations.

(C) 2020 by the authors. Licensee MDPI, Basel, Switzerland. This article is an open access article distributed under the terms and conditions of the Creative Commons Attribution (CC BY) license (http://creativecommons.org/licenses/by/4.0/). 